\title{
Competitive and Cooperative Degree in Supply Chain: Supplier Selection between Competitors and Third-Party Suppliers
}

\author{
Bo Xie ${ }^{1}$, Xianjia Wang ${ }^{1}$, and Chuan Zhou ${ }^{2}$ \\ ${ }^{1}$ Wuhan University, Economics and Management School, 430072 Wuhan, China \\ xie040304@gmail.com \\ ${ }^{2}$ Chian Unicom, 471001 Luoyang, China \\ bo6193@163.com
}

\begin{abstract}
This work explores the firm's supplier selection question that the competitor firm and the third-party supplier can supply the substitutable component. We consider a supply chain with two competing original equipment manufacturers (OEMs) and two third-party suppliers. The two OEMs produce the competing products which are comprised by two main components. Each OEM only can produce one component in-house and each third-party supplier only supplies one component. The OEMs must decide whether to outsource the other component to the competing OEM or to a third-party supplier. We discuss the different supplier selection strategies and compare the OEMs profits in different decision. We find that there are conditions where, while one of the OEMs should outsource to the competing firm, outsourcing to a third-party supplier is the optimal strategy for the other OEM even when the cost of the third-party supplier is more expensive and the competition is intense.
\end{abstract}

Keywords: Outsourcing selection, Co-opetition, Price competition.

\section{Introduction}

Competitors Nissan and Daimler's Mercedes are both outsourcees and outsourcers of one another. In particular, Nissan uses Daimler's Mercedes front-wheel-drive architecture platform for its Infiniti luxury vehicle and supplies Daimler with diesel and gas engines [1]. Moreover, Samsung and Google, Leica and Panasonic also compete with the end product in the market and supply the component to each other in the component wholesale market [2] [3]. We call this relationship is co-opetition. The previous research literature (e.g., [4] [5] [6]) has researched the co-opetition problem about the competing firms and points out that the competitor can earn revenue from both competing products with two firms cooperation. Consequently, the competitor will not price its own product aggressively, thus leading to a lower degree of competition.

In this paper, we consider the supplier-selection problem of two competing OEMs. The OEMs can produce one component in-house and must outsource the other component to a third-party supplier or to the competing OEM. We consider the case 
where competing OEMs will cooperate as supply-chain partners only if their total profit is higher than that they can get if they do not cooperate.

\section{$2 \quad$ Literature Review}

Our work in this paper relates to the stream of research on the topic of forming a supply-chain relationship with competitors. Bengtsson and Kock [7] define the coopetition as a strategy embodying simultaneous cooperation and competition between firms. Gnyawali and Park [8] investigate why and how co-opetition between large firms and impact the participating firms and the industry. Venkatesh et al. [4] find that the manufacturers of proprietary component brands often have the ability to effect for the end-products and face to choose its role from sole entrant, co-optor and component supplier in the market. Lim and Tan [9] focus on the outsourcing of the supplier as a direct competitor of the buyer firm in the downstream marketplace. Wang et al. [6] investigate the advantage of being the first mover when a contract manufacturer acts as both supplier and competitor. Moreover, Pun [10] considers the supplier selection of a manufacturer can either outsource to an independent supplier or to its competitor when the firm wants to do R\&D for the end-product.

Our paper differs from these papers in the following ways: First, we assume that there are two OEMs competing in the market and each of them can supply the component with its brand. Second, in our paper, we assume that there is price competition for the OEMs in the market. The OEM's decision about the outsourcing will have impact for total profit. To the best of our knowledge, the case that the competing OEMs supply the component to each other is a new type in supply chain.

\section{Model Framework}

We consider a supply chain with two OEMs (firms G and S) and two third-party suppliers and each OEM sales a competing product. And each product consists of two main components, A and B. Firm G (firm S) produces component A (component B) in-house and must outsource component B (component A) either to a third-party supplier firm B (firm A) or to the competing OEM firm S (firm G). The basic frame work of the model is similar to that in Pun and Bo [11]. The OEM and the third-party supplier each produce the component with different costs. Specifically, the production cost of the OEMs is normalized to zero, and the production cost of the third-party suppliers is $\Delta c$, so that the third-party suppliers have higher production cost when $\Delta c>0$ and the OEMs have higher production cost when $\Delta c<0$. We use the demand model presented by McGuire and Staelin [12] and Staelin [13]. Specifically, the demand of the end-product of firm $i \in\{G, S\}$ is as follows:

$$
D_{i}=1-\frac{1}{1-\theta} p_{i}+\frac{\theta}{1-\theta} p_{\bar{i}}
$$

$\bar{i}$ is the competitor of firm $i$ and $p i$ is the price of product $i .0 \leq \theta<1$ is the degree of competition between the two products, so that the two products are not competing when $\theta$ is zero and competition increases in $\theta$. 
In this game, the two OEMs first choose the outsourcing strategy. Then, as commonly assumed in the literature (e.g. [14] [15] [16]), the suppliers set the wholesale price $w$ simultaneously. Lastly, the two competing OEMs choose the retail price $p$. The OEM can choose to outsource to the competing OEM or to the third-party supplier. We use the abbreviations $\mathrm{T}$ and $\mathrm{C}$ (Third-party supplier and Competing OEM) to denote the different suppliers and the first letter to denote the component supplier for firm $\mathrm{G}$ and the second letter for firm $\mathrm{S}$. As a result, we will get four strategies as $\{\mathrm{TT}, \mathrm{TC}, \mathrm{CT}, \mathrm{CC}\}$, where TT denotes that firm $\mathrm{G}$ outsources to the third-party supplier and firm $\mathrm{S}$ outsources to the third-party supplier. Since strategy TC and strategy CT are symmetrical, without loss of generality, we omit the results of strategy CT to avoid redundancy.

Table 1. The profits of firms in different strategies

\begin{tabular}{llll}
\hline Firm & Strategy TT & Strategy TC & Strategy CC \\
\hline G (OEM) & $\left(p_{G}-w_{B}\right) D_{G}$ & $\left(p_{G}-w_{B}\right) D_{G}+w_{G} D_{S}$ & $\left(p_{G}-w_{S}\right) D_{G}+w_{G} D_{S}$ \\
S (OEM $)$ & $\left(p_{S}-w_{A}\right) D_{S}$ & $\left(p_{S}-w_{G}\right) D_{S}$ & $\left(p_{S}-w_{G}\right) D_{S}+w_{S} D_{G}$ \\
A $\left(3^{\text {rd }}\right.$-party $)$ & $\left(w_{A}-\Delta c\right) D_{S}$ & 0 & 0 \\
B (3 $3^{\text {rd }}$-party $)$ & $\left(w_{B}-\Delta c\right) D_{G}$ & $\left(w_{B}-\Delta c\right) D_{G}$ & 0 \\
\hline
\end{tabular}

In the next analysis, we will use $\pi_{G}$ and $\pi_{S}$ to represent the profits of the two OEMs. And we use superscripts to denote the outsourcing strategy. For example, $\pi_{S}^{T C}$ represents the profit of firm $S$ under strategy TC. Specifically, firm G and firm $S$ will cooperate (strategy TC or CC) only if they can earn higher total profits than they do under strategy TT. For notational convenience, let the total profit of the two firms be $\pi_{G S}=\pi_{G}+\pi_{S}$. Then the two competing OEMs will choose the strategy that gives them the largest total profit.

\section{$4 \quad$ Analysis}

In this section, we will compare total profit and present the optimal outsourcing strategy. Throughout the analysis, we will focus on the region where demands of both products are positive. We consider another strategy that two OEMs both produce the two main components in-house and use $\pi_{G S}^{I I}$ as the total profit under this strategy. We will compare the total profit in the following and discuss the competition and cooperation.

Proposition 1. The comparisons of the total profit of the two OEMs are as follows.
a. $\pi_{G S}^{I I}>\pi_{G S}^{T T} \Leftrightarrow \Delta c>\Gamma_{0}(\theta)$,
b. $\pi_{G S}^{I I}>\pi_{G S}^{C C} \Leftrightarrow \theta<\sqrt{13}-3$,
c. $\pi_{G S}^{T T}<\pi_{G S}^{C C} \Leftrightarrow \Delta c>\Gamma_{1}(\theta)$,
d. $\pi_{G S}^{T T}<\pi_{G S}^{T C} \Leftrightarrow \Delta c>\Gamma_{2}(\theta)$,
e. $\pi_{G S}^{T C}<\pi_{G S}^{C C} \Leftrightarrow \Gamma_{3 a}(\theta)<\Delta c<\Gamma_{3 b}(\theta)$. 
It has been shown that selling through third-party retailers can mitigate competition between competing manufacturers (e.g. [12]). Proposition 2a states that competition between OEMs can also be mitigated with outsourcing to the third-party suppliers. In particular, when the two products are independent $(\theta=0)$, the OEMs should produce both components in-house (strategy II) in order to eliminate the inefficiency of double marginalization unless the third-party supplier has a very low cost

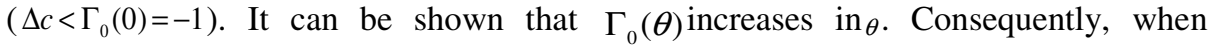
compared to strategy II, strategy TT becomes more valuable as competition intensifies since outsourcing to a third-party supplier can mitigate competition.

Since the third-party suppliers are not responsible for producing any of the components under strategies II and CC, the comparison of the total profit between these two strategies remains independent of $\Delta c$ (cf. Proposition 2b). Two drivers in particular have an impact on the comparison between strategies II and CC. First, outsourcing to a competitor can minimize competition; second, producing all components in-house can eliminate the inefficiency of double marginalization. When all firms have the same production costs $(\Delta c=0)$, Proposition 2a shows that the advantage of mitigating competition by outsourcing to a third-party supplier is smaller than the inefficiency of double marginalization introduced by deploying strategy TT. Consequently, the total profit is larger under strategy II than it would be under strategy TT, regardless of the degree of competition. Proposition $2 \mathrm{~b}$ extends the result of Proposition 2a by illustrating that, compared with outsourcing to a third-party supplier, outsourcing to a competitor is more effective in mitigating competition. In particular, when competition is sufficiently strong $(\theta>\sqrt{13}-3)$ and all firms have the same production costs ( $\Delta c=0$ ), the two OEMs are better off mitigating competition by deploying strategy $\mathrm{CC}$ than by deploying strategy II despite incurring the inefficiency of double marginalization.

Proposition $2 \mathrm{c}$ further illustrates that outsourcing to a competitor does a better job of mitigating competition compared to a strategy of outsourcing to a third-party supplier. Specifically, when the level of competition between the two products is intermediate (e.g., $\theta=1 / 2$ ), then mitigating competition is marginally valuable, and the total profit under strategy $\mathrm{CC}$ is higher as long as the costs of the third-party suppliers are sufficiently high $\left(\Delta c>\Gamma_{1}(1 / 2) \approx-0.62\right)$. When the level of competition is intense ( $\theta \rightarrow 1$ ), mitigating competition becomes very important and, hence, strategy $\mathrm{CC}$ is always superior to strategy $\mathrm{TT}$, even when the third-party suppliers costs are extremely low $\left(\Delta c>\lim _{\theta \rightarrow 1} \Gamma_{1}(\theta)=-\infty\right)$. It can be shown that $\Gamma_{2}(0)=\Gamma_{3 b}(0)$ (cf. Propositions $2 \mathrm{~d}-\mathrm{e}$ ). Therefore, depending on the relative cost efficiency between the OEMs and the third-party suppliers, when there is no competition, the OEMs would choose between two options: both would outsource to one another or both would outsource to third-party suppliers. When there is no competition, the firms are never better off in deploying the asymmetric strategy (strategy TC). In the presence of competition, however, the comparisons of the total profit under strategies TT, TC and CC are not monotonic in the degree of cooperation between the two competing OEMs. Specifically, Proposition 2d shows that some degree of cooperation between competitors (strategy TC) is better than no cooperation 
(strategy TT) as long as the third-party suppliers' costs are larger than $\Gamma_{2}(\theta)$. As $\theta$ increases, $\Gamma_{2}(\theta)$ decreases, hence, a certain degree of cooperation (strategy TC) becomes relatively more valuable when compared to strategy TT because the thirdparty suppliers must be relatively more cost effective $\left(\Gamma_{2}(\theta)\right.$ more negative) for strategy TT to be optimal. However, Proposition 2e demonstrates that maximum cooperation (strategy CC) is not always better than some cooperation (strategy TC). When the degree of competition is small, it can be shown that the total profit under maximum cooperation (strategy CC) is larger than what it would be under some degree of cooperation (strategy TC) as long as the third-party suppliers' costs are not too low $\left(\Delta c>\Gamma_{3 a}(\theta)\right.$ where $\left.\Gamma_{3 a}(\theta)<0\right)$. However when competition is strong, we find that $\pi_{G S}^{T C}$ is larger than $\pi_{G S}^{C C}$ when the OEMs' costs are similar to those of the thirdparty suppliers. Therefore, cases do exist where the total profit under strategy TC is larger than it would be under strategy $\mathrm{CC}$ in spite of the cost disadvantage of the third-party supplier $(\Delta c>0)$. We present the optimal strategy in Proposition 3. The outside region represents the cases in which no demand of both products is positive.

Proposition 2. The optimal outsourcing strategy is presented in Fig. 1.

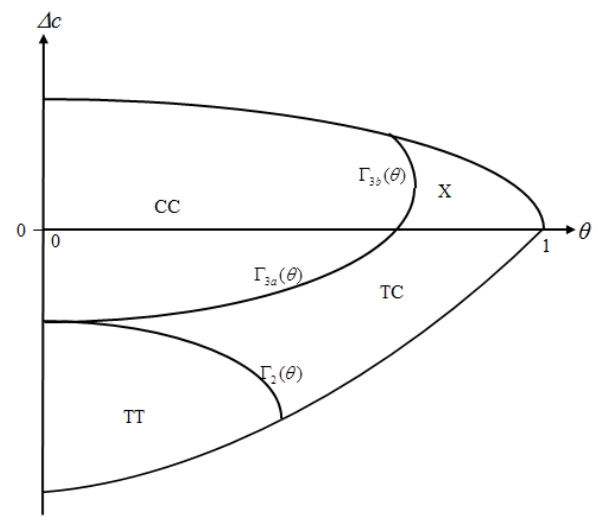

Fig. 1. Optimal outsourcing strategy

When being the outsourcee of the competitor (firm S), the OEM (firm G) can have two revenue sources: one from the wholesale market and the other from the end product market. Therefore, when there is no competition between the two competing products $(\theta=0)$, the two OEMs will outsource to one another (strategy CC). However, if the third-party supplier is significantly more cost effective $(\Delta c<<0)$, they will outsource to the third-party supplier (strategy TT).

Previous research has shown that competitors cooperating as supply-chain partners can minimize competition. Therefore, one might expect that when competition intensifies ( $\theta$ increases), the region where strategy $\mathrm{CC}$ is optimal will also increase because there is more cooperation under strategy $\mathrm{CC}$ than that of strategy TC. We find, however, that this insight might not hold. The total profit of both OEMs consists 
of two drivers. The first is the relative cost efficiency between the OEMs and the third-party suppliers $\Delta c$, and, numerically, we observe that this relative production cost has more impact to the total profit under strategy $\mathrm{CC}\left(\pi_{G S}^{C C}\right)$ than to the total profit under strategy TC $\left(\pi_{G S}^{T C}\right)$. The other factor that affects the total profit is the degree of competition between the two products $(\theta)$. We find that the total profit under strategy TC is more likely to be larger than it would be under strategies TT and CC when $\theta$ is large (cf. Proposition 2). As a result, one of the firms can be better off outsourcing to the third-party supplier (strategy TC), even when the third-party supplier's production costs are higher than those of the competitor and when the competition is strong (cf. Point $\mathrm{X}$ in Fig. 1).

Next, we extend our results by altering some assumptions in the model. We assume the difference between third-party supplier and competing OEM is the quality of the components rather than the cost. Under this discussion, the basic framework of the model and the game sequence are similar to that in the previous discussion but the demand function is different. All firms have the same production costs $(\Delta c=0)$.

$$
D_{i}=Q_{i}(N)-\frac{1}{1-\theta} p_{i}+\frac{\theta}{1-\theta} p_{\bar{i}}, \quad Q_{i}(N)= \begin{cases}\alpha & N=C \\ 1 & N=T\end{cases}
$$

The solution process in this section can be proved in the same way as in the previous solution, respectively, and thus the proofs are omitted for brevity. We just summarize the main findings here.

Proposition 3. The optimal outsourcing strategy is presented in Fig. 2 and is expressed mathematically as follows (where $\Lambda, \Gamma$ and $\gamma$ are threshold value).

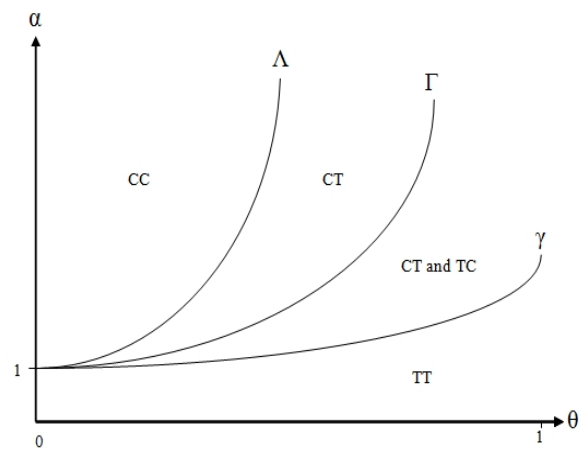

Fig. 2. Optimal Outsourcing Strategy for Different Quality

When $\alpha<\gamma$, the equilibrium strategy is that firm $\mathrm{G}$ and firm $\mathrm{S}$ both choose to outsource to the third-party suppliers so that they are just pure competitors in the market. It is because when $\alpha$ is small, outsource to the third-party supplier is better. When $1<\alpha<\gamma$, outsourcing to the third-party supplier, OEM will also get the larger profit than outsourcing to the competitor. When $\Lambda<\alpha$, the best choice for both OEMs 
is outsourcing the ingredient to each other, even in this case OEMs could not price its product aggressively. When compared to the profit of OEMs under others strategies, it shows that both OEMs get the largest profit for outsourcing to each other (strategy CC).

And we consider the case where outsourcing to competitor, the OEM will get high quality end-product (i.e., $\alpha>1$ ). In strategy $\mathrm{CT}$, firm $\mathrm{G}$ will get the high quality end-product with outsourcing to firm $\mathrm{S}$ and firm $\mathrm{S}$ just outsources to the third-party supplier. The demands and the prices of firm $\mathrm{G}$ and firm $\mathrm{S}$ are better off with the increases of $\alpha$ simultaneously in strategy CT. We know when firm $\mathrm{G}$ outsources to the competitor firm $\mathrm{S}$; it will manufacture the different quality end-product. With $\alpha>1$, the quality of firm G's end-product is high. The high quality end-product brings the larger total market demand for firm $G$ and therefore allows firm $G$ to charge a higher price. Since firm $\mathrm{G}$ charges a higher price which has the positive impact on firm S's end-product demand even firm S's total market demand is unchanged. So the demand of firm $\mathrm{S}$ is also increasing and allows firm $\mathrm{S}$ to charge a higher price even its end-product's quality is lower than that of firm G. We also get that the increasing speed of price for firm $G$ is faster than it for firm $S$ (i.e., $\frac{\partial P_{G}^{C T}}{\partial \alpha}>\frac{\partial P_{S}^{C T}}{\partial \alpha}$ ). As a result, the demands and the prices for both OEMs are better off with $\alpha$ increasing in strategy CT (strategy TC).

Next, consider the case where outsourcing to competitor, the OEM will get low quality end-product (i.e., $\alpha<1$ ). In strategy $\mathrm{CT}$, firm $\mathrm{G}$ will get the low quality end-product with outsourcing to firm S. We know that the demands and the prices of firm $\mathrm{G}$ and firm $\mathrm{S}$ are better off with the increases of $\alpha$ simultaneously in strategy CT. With $\alpha$ increasing, the total market demand of firm $\mathrm{G}$ is increasing even which is less than that of firm S. The increasing total market demand allows firm $\mathrm{G}$ to charge a higher price. When firm $\mathrm{G}$ charges the higher price, firm $\mathrm{S}$ will get larger end-product demand since the price of firm $G$ has the positive impact on firm S's demand and allowing firm $\mathrm{S}$ to charge a higher price. And we can know $\frac{\partial P_{G}^{C T}}{\partial \alpha}>\frac{\partial P_{S}^{C T}}{\partial \alpha}$. So we get the result that the demands and the prices for both OEMs are better off with $\alpha$ increasing in strategy CT even $\alpha<1$. Similarly, in strategy $\mathrm{TC}$, the demands and the prices of firm $\mathrm{G}$ and firm $\mathrm{S}$ are better off with the increasing of $\alpha$ simultaneously in strategy TC.

So we know that under strategy CT and strategy TC, the demand and the price of the both OEMs will increase consistently whether $\alpha>1$ or $\alpha<1$.

\section{Conclusion}

In this paper we talk about the outsourcing strategy of two OEMs. Because the cooperation between the competitors could reduce the competition, people think more cooperation is the better. But in the research, we find that since two OEMs have the price competition in the market, one OEM had better outsource to the third-party supplier even if the competitor OEM's production cost is lower. So the cooperation degree is important. 
We research the supplier selection question with some limitations. First we assume that the information about the production cost is complete information. When the cost is private, we must think about the information sharing or information leakage question. Second, we study the market where the demand of the market is certain. If the demand is uncertain, the firm must think about the inventory problem and leftover problem. These will make the supply chain inefficient.

\section{References}

1. Nissan, C.L.: Daimler planners confer weekly on more deals. Automotive News 86(6512) (2012)

2. Marketing Weekly News. Panasonic introduces ultra-slim LUMIX digital cameras with 10x optical zoom and wide-angle Leica lens. Marketing Weekly News (January 2012)

3. Digital Life. Leica goes digital. Digital Life (February 2007)

4. Venkatesh, R., Chintagunta, P., Mahajan, V.: Research note-sole entrant, co-optor, or component supplier: optimal end-product strategies for manufactures of proprietary component brands. Management Science 52(4), 613-622 (2006)

5. Xu, Y., Gurnani, H., Desiraju, R.: Strategic supply chain structure design for proprietary component manufacturer. Production and Operations Management 19(4), 371-389 (2010)

6. Wang, Y., Niu, B., Guo, P.: On the advantage of quantity leadership when outsourcing production to a competitive contract manufacturer. Production and Operations Management 22(1), 104-119 (2013)

7. Bengtsson, M., Kock, S.: "Coopetition" in business networks-to cooperate and compete. Industrial Marketing Management (29), 411-426 (2000)

8. Gnyawali, D.R., Park, B.J.: Co-opetition between giants: Collaboration with competitors for technological innovation. Research Policy 40(2011), 650-663 (2011)

9. Lim, W.S., Tan, S.J.: Outsourcing suppliers as downstream competitors: biting the hand that feeds. European Journal of Operational Research 203(2), 360-369 (2010)

10. Pun, H.: Supplier selection when the production process can be improved. Working Paper

11. Pun, H., Bo, X.: The more the better? Optimal degree of supply-chain cooperation between competitors. Working Paper (2013)

12. McGuire, T., Staelin, R.: An industry equilibrium analysis of downstream vertical integration. Marketing Science 2(2), 161-191 (1983)

13. Staelin, R.: Commentary - an industry equilibrium analysis of downstream vertical integration: Twenty-five years later. Marketing Science 27(1), 111-114 (2008)

14. Gerchak, Y., Wang, Y.Z.: Revenue-sharing vs. wholesale-price contracts in assembly systems with random demand. Production and Operations Management 13(1), 23-33 (2004)

15. Granot, D., Yin, S.Y.: Competition and cooperation in decentralized push and pull assembly systems. Management Science 54(4), 733-747 (2008)

16. Nagarajan, M., Sosic, G.: Coalition stability in assembly models. Operations Research 57(1), 131-145 (2009) 